\title{
Thrombus on Mitral Prosthetic Valve - An Uncommon Complication
}

\author{
M Rahman, MM Rahman, B Chakraborty, ASMN Islam
}

Department of Cardiology, Labaid Cardiac Hospital, Dhaka.

\section{Keywords: \\ Prosthetic valve, Thrombus,} Thrombolytic.

\section{Case history}

A 37 yrs old Bangladeshi lady was admitted in Labaid Cardiac Hospital with severe shortness of breath for 1 day. She had metallic Mitral Valve Replacement (MVR) in 2002 for severe Mitral Regurgitaion of rheumatic origin. Since then she has been on warfain and doing well. Three days prior to her admission she had a Dilatation \& Curettage (Menstrual regulation) and stopped warfain as advised by the Gynaecologist.

On admission she was found severely dyspnoic and cyanosed. Her blood pressure was not recordable, peripheral pulses were feeble. On auscultation, her heart sounds were muffled and opening click was very soft. There was no audible murmur.

Lungs were full of crepitations upto upper zones. She was having fast atrial fibrillation (AF) with marked tachypnoea with very low oxygen saturation and her mental state was obtunded. She developed anuria before admission. She was in a state of cardiogenic shock.

She was urgently intubated and kept on mechanical ventilator with maximum dose of inotropes.

Bedside echo showed hugely dilated Left Atrium poor visualization of leaflets of metalic valve. There was almost no movement of the prosthetic valve leaflets. Doppler study showed increased pressure gradients (PPG $29 \mathrm{mmHg}$, MPG $12 \mathrm{mmHg}$ ) across the Mitral Valve (MV) with increased pressure half time (PHT $656 \mathrm{~ms})$.

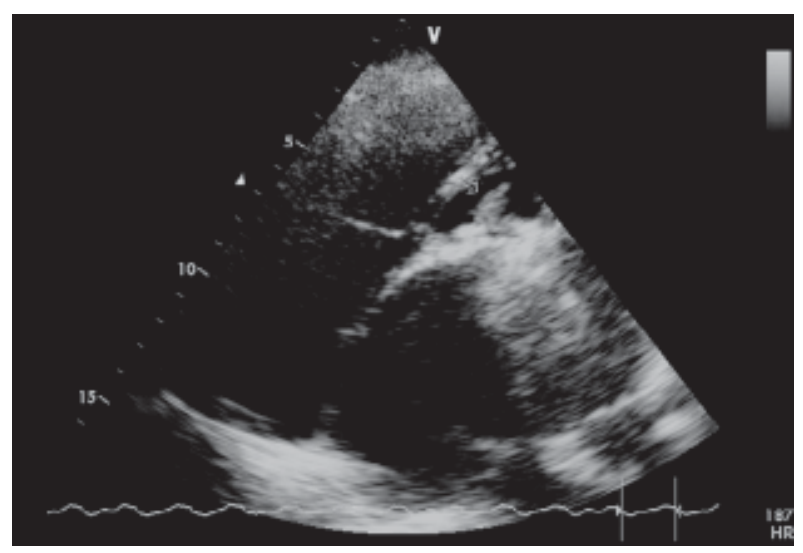

Fig.-1: Thrombus in the Mitral Prosthetic Valve (Before treatment)

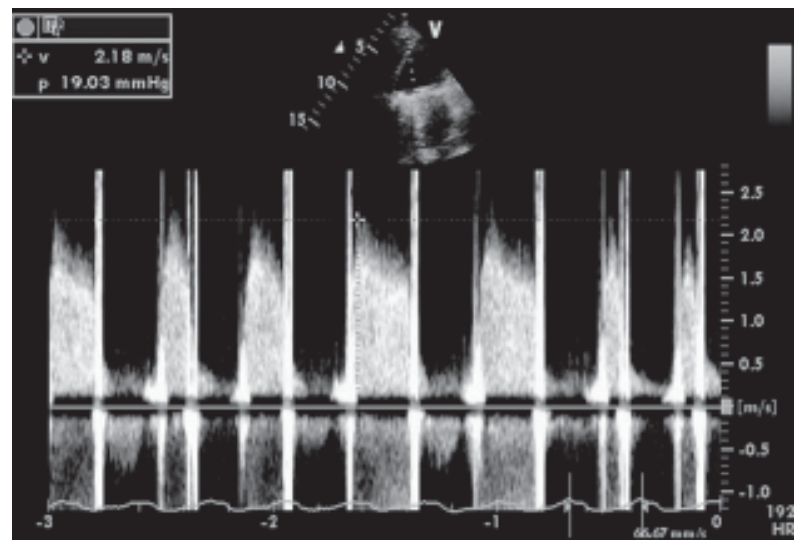

Fig.-2: Peak pressure gradient across the mitral valve (Before treatment)

Immediately Inj. Streptokinase (STK) was started with 2,50,000 units IV bolus over $30 \mathrm{~min}$, then $1,00,000$ units / hr. as continuous infusion for 24 hours.

Address Correspondence : Dr. Mahbubor Rahman, Department of Cardiology, Lab Aid Cardiac Hospital, Dhaka.

Email: mahbubordr @ yahoo.com 
After 5 hrs of thrombolytic (STK) infusion patient's blood pressure started to rise, urine flow improved, oxygen saturation came towards normal levels. Bedside echo showed better visualization of prosthetic valve with a prolapsing flame shaped dissolving thrombus between the leaflets of valve. Pressure gradients across the valve started to decline (PPG $18 \mathrm{mmHg}$ ) and PHT also started to reduce (180 ms).

In the next morning patient showed remarkable improvement from haemoaynamic point of view and her urine output was satisfactory. Beside echo showed complete resolution of thrombus, normalization of pressure gradients and PHT. Patient was treated with a combination of I/V heparin and warfarin at the same time.

Patient was extubated on the third day and she was able to maintain her oxygen saturation and hemodynamics nicely. After three days of infusion, heparin was stopped and she was discharged from the hospital with optimal dose of oral anticoagulant.

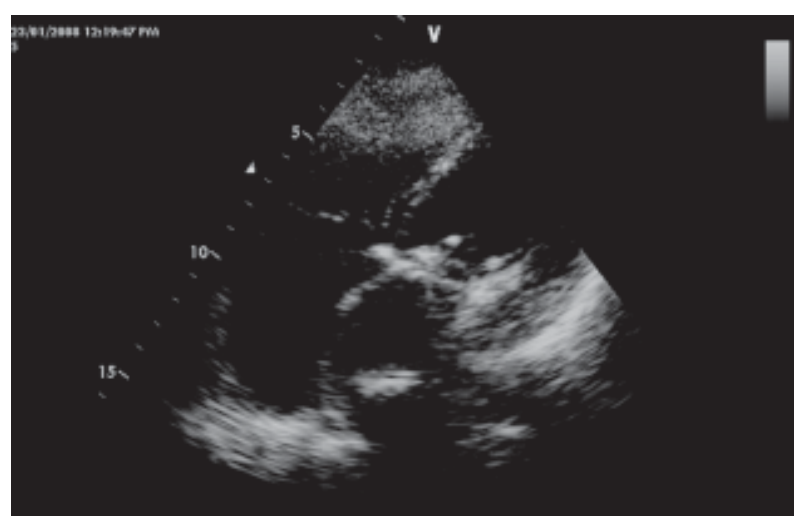

Fig.-3: Mitral Prosthetic Valve free of thrombus (after treatment)

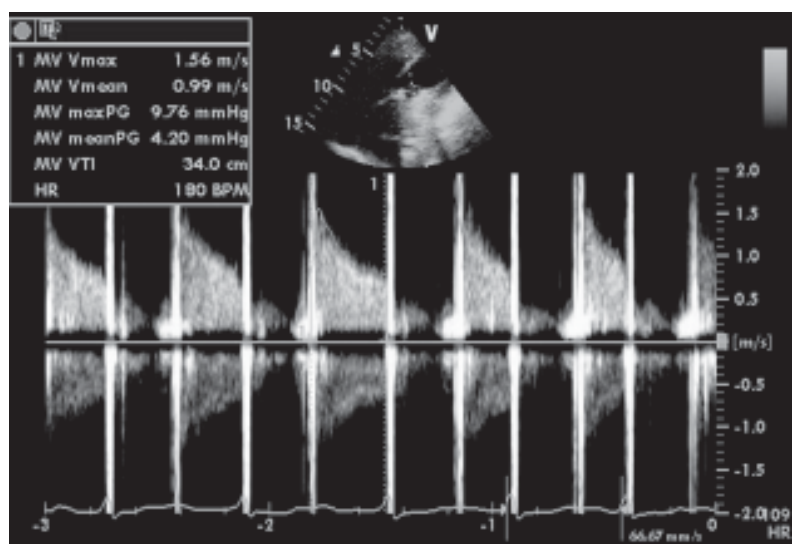

Fig.-4: Peak pressure gradient across the mitral valve (After treatment)

\section{Discussion:}

Thrombosis and thromboembolism risks are greater with any mechanical valve in the mitral than in the aortic position. ${ }^{1}$

Without anticoagulants and aspirin, the incidence of thromboembolism is threefold to sixfold higher than when proper doses of these medications are administered. Rarely, thrombosis of the mechanical valve occurs. This may be a fatal event, but when nonfatal, it interferes with prosthetic valve function. ${ }^{2}$

Warfarin should begin about 2 days after operation and INR should be in the range of 2.0 to 3.0 for patients with bi-leaflet disc in the aortic position and between 2.5 and 3.5 for patients with all valves in mitral position. ${ }^{1}$

Antiplatelet agents without anticoagulants do not provide adequate protection. However, addition of Aspirin, 80 to $150 \mathrm{mg}$ daily, together with warfarin may reduce the risk of thromboembolism and should be given to all patients with prosthetic valve. ${ }^{1}$

Prosthetic valve thrombosis should be suspected by the sudden appearance of dyspnea and muffled sounds or new murmurs on auscultation. This serious complication is diagnosed by transesophageal echocardiography. Echocardiographic evaluation for prosthetic valve thrombus is limited, except with very large masses, due to shadowing and reverberation. In addition, clinical events may be associated with clots smaller than the limits of clinical ultrasound resolution. Thus, echocardiography cannot exclude the possibility of thrombus on a prosthetic valve. ${ }^{3}$ However in our case, thrombus was so big that it was clearly diagnosed by transthoracic echocardiography.

Treatment consists of infusion of a thrombolytic agent for 24 to 72 hours, heparin and aspirin. Surgery is required for nonresponders and for patients with mobile thrombus. ${ }^{4}$

Despite treatment with anticoagulants, the incidence of thromboemlolic complications with the best mechanical prosthesis is still not uncommon. About 0.2 fatal complication and 1.0 to 2.0 nonfatal 
complications per 100 patient-years for aortic valves and 2.0 to 3.0 nonfatal complications for mitral valves occur. Valve thrombosis occurs at an incidence of about 0.1 percent per year in the aortic position and 0.35 percent per year in the mitral position. $^{2}$

\section{Conclusion:}

We must give emphasis on continuing anticoagulation with warfarin therapy to achieve desired INR level. Aspirin, 50 to $100 \mathrm{mg}$ daily, should be added, if not contraindicated, to all mechanical prosthetic valve patients.

\section{References:}

1. Bonow RO, Carabello B, et al : ACC/AHA guidelines for the management of patients with valvular heart disease. J Am Coll Cardiol 32: 1486, 1998.

2. Bonow RO, Branuwald E. Valvular Heart Diseases, In Zipes. Libby. Bonow, Branuwald. Eds. Branuwald's Heart Disease. $7^{\text {th }}$ edition. Elsevier Saunders, Philadelphia, USA 2005; 1609-1610.

3 Otto CM. Prosthetic Valves. In : Textbook of clinical echocardiography. $3^{\text {rd }}$ Edition, Elsevier Saunders. Philadelphia, USA. 2004; 359-360.

4. Lengyel M. Fuster V. Keltai M. et. al : Guidelines for management of left-sided prosthetic valve thrombosis : A role for thrombolytic therapy. J Am coll Cardiol. 30 : 1521, 1997. 